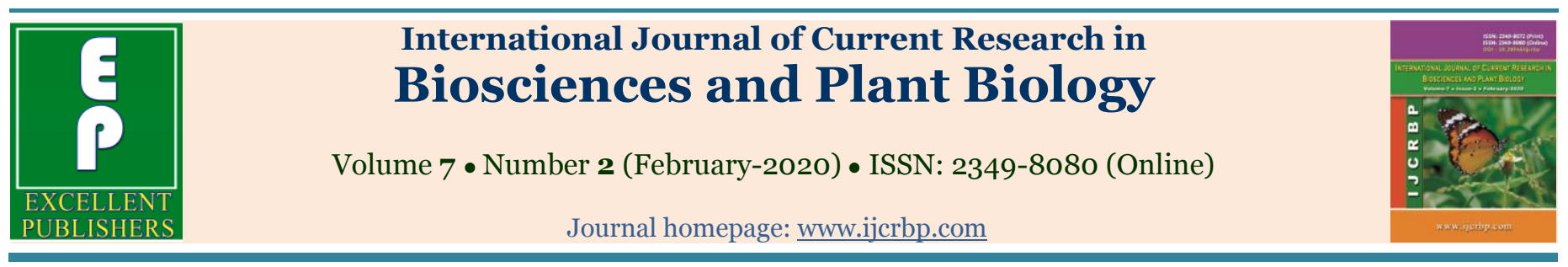

\title{
Individual effects of sucrose, kinetin and salicylic acid and combined effects of kinetin + sucrose and salicylic acid + sucrose in petal senescence regulation of Aster novae belgii L.
}

\author{
S. Mukherjee' and D. Mukherjee ${ }^{2 *}$
}

\begin{abstract}
1The Institute of Integrated \& Honors Studies, Kurukshetra University, Kurukshetra - 136119, India
${ }^{2}$ Department of Botany, Kurukshetra University, Kurukshetra - 136119, India

${ }^{*}$ Corresponding author; e-mail: dibumukherjee@gmail.com
\end{abstract}

\begin{tabular}{|c|c|}
\hline Arti & ABSTRACT \\
\hline $\begin{array}{l}\text { Date of Acceptan } \\
15 \text { January } 2019\end{array}$ & \multirow{3}{*}{$\begin{array}{l}\text { Senescence regulation in Aster novae belgii petals was studied by taking mature cut } \\
\text { scapes (flower twigs without leaves). Scapes were placed in holding solutions of o.1M } \\
\text { sucrose, } 37.5 \mu \mathrm{M} \text { kinetin }(\mathrm{KN}), 37.5 \mu \mathrm{M} \text { salicylic acid (SA), KN }(37.5 \mu \mathrm{M})+\text { sucrose } \\
(\mathrm{O}-1 \mathrm{M}), \mathrm{SA}(37.5 \mu \mathrm{M})+\text { sucrose }(0.1 \mathrm{M}) \text { and double distilled water (DDW). Untreated } \\
\text { petals exhibited loss of turgidity and shrinkage earlier than those received treatments of } \\
\text { either a sugar (sucrose) or a plant growth regulator (PGR) like KN or SA. Among the } \\
\text { individual treatments, sucrose was the best followed by KN and SA in slowing down the } \\
\text { reduction in flower diameter, starch depletion, sugar accumulation and increment in } \\
\text { lipid peroxidation. Among the combined applications, KN in presence of sucrose } \\
\text { showed more promising effect in delaying petal senescence of cut Aster flowers. This } \\
\text { combination could also reduce } \alpha \text {-amylase and peroxidase activity. Among all } \\
\text { treatments the order of effectiveness was KN + sucrose }>\mathrm{SA}+\text { sucrose }>\text { sucrose }>\mathrm{KN} \\
>\mathrm{SA}>\text { DDW. }\end{array}$} \\
\hline Keywords & \\
\hline & \\
\hline
\end{tabular}

\section{Introduction}

Plants and plant parts enter a phase of senescence after passing through growth and earlier stage of development. Senescence is characterized by various morphological, physiological and biochemical changes leading to deterioration (Beevers, 1976). Flower senescence represents the last stage of floral development exhibiting wilting or abscission of whole flowers or flower parts (Stead and van Doorn, 1994; Mukherjee and Mukherjee, 2017). Cut flowers are highly perishable commodities and are marketed for ornamental purpose. Their freshness and turgidity are lost rapidly as supply of water and nutrients become a limiting factor. Short post-harvest life is one of the most important problems of cut flowers. Several studies have been carried out extensively to find out how vase life of cut flowers can be extended (Rubinstein, 2000). Sugars like sucrose can maintain the flower quality and extend shelf and vase life; being the source of carbon and energy (Kuiper et al., 1995; Monteiro et al., 2002; van Doorn, 2004; Mukherjee and Mukherjee, 2017). Sucrose is able to maintain the turgidity in cut flowers by increasing the osmotic concentration of petal cell sap when present in the vase solution (O'Donoghue et al., 2002). Sugars 
(including sucrose) are known to postpone senescence by suppressing ethylene synthesis in both cut and uncut flowers. Ethylene is a gaseous plant growth regulator (PGR) directly associated with petal senescence besides its other effects (Woltering and van Doorn, 1988). Although separate studies have been carried out with sugars and PGRs to improve vase life of cut flowers and to delay petal senescence, fewer attempts have been made to investigate collective effectiveness of sucrose and PGR (Mukherjee and Mukherjee, 2017; Mukherjee et al., 2019). This idea prompted us to carry out investigation on cut flowers of Aster novae belgii to compare not only individual effects of sucrose, kinetin (KN) and salicylic acid (SA) but also interaction of sucrose $+\mathrm{KN}$ and sucrose $+\mathrm{SA}$ as vase solutions.

\section{Materials and methods}

\section{Plant material}

Aster novae belgii L. plants were grown in the uniformly prepared experimental plots of the Botany Department, Kurukshetra University, Kurukshetra. Uniform flowers of the same age and morphological appearance were collected for five treatments. Flowers were cut under water and brought to the laboratory. Leaves were removed from the flower twigs and were recut under distilled water to obtain scapes having $14 \mathrm{~cm}$ length. These scapes were transferred to $100 \mathrm{ml}$ conical flasks (Borosil make), each one containing $30 \mathrm{ml}$ holding solutions. For each treatment and also for control (double distilled water, DDW) five conical flasks were maintained. Holding solutions were sucrose $(0.1 \mathrm{M})$, kinetin $(\mathrm{KN}, 37.5 \mu \mathrm{M}), \mathrm{KN}$ $(37.5 \mu \mathrm{M})+$ sucrose $(0.1 \mathrm{M})$, salicylic acid (SA, 37.5 $\mu \mathrm{M})$ and SA $(37.5 \mu \mathrm{M})+$ sucrose (o.1M). Control sets with DDW were also maintained for comparison. Flower diameter was recorded at 0,4 and 8-day while volume of holding solution absorbed were recorded on initial and $8^{\text {th }}$ day.

Petal samples were collected in triplicates for the estimation of sugars (reducing, non- reducing and total sugars), starch, $\alpha$-amylase activity, peroxidase activity and MDA content.

\section{Estimation of starch and sugars}

The method of Hart and Fisher (1971) using anthrone-sulphuric acid reagent was followed for the estimation of starch and sugars. Details about the method has been mentioned earlier (Mukherjee and Mukherjee, 2017). For the starch estimation the absorbance was read at $630 \mathrm{~nm}$ in a UV-Vis Spectrophotometer. Absorbance for reducing sugars was measured at $600 \mathrm{~nm}$ whereas for total sugars it was noted at $625 \mathrm{~nm}$. Subtracting the amount of reducing sugars from the value of total sugars, the amount of non-reducing sugars will be obtained. Starch and sugars were quantified in terms of glucose using standard curves.

\section{Extraction and estimation of individual sugars}

Flower sample (2 g each) was homogenized with $60 \mathrm{ml}$ of $80 \%$ ethyl alcohol. It was filtered and filtrate was collected in evaporating dish. The residue was re-extracted thrice with $80 \%$ ethyl alcohol and filtrates were collected in the same evaporating dish. Extract was evaporated with cold current of air and allowed to dry at room temperature. Evaporated mass was dissolved in $5 \mathrm{ml}$ of $20 \%$ ethyl alcohol followed by centrifugation at $5000 \mathrm{rpm}$ for $10 \mathrm{~min}$. Clear supernatant was collected and stored for chromatographic analysis.

Whatman paper no. 1 was used for the separation of samples and the size of the strip was $28 \times 8 \mathrm{~cm}^{2}$. Samples were applied on the strips. Solvent system used for the chromatographic run was n-butanol acetic acid - distilled water (DDW) in the ratio of 4:1:5 (upper layer). Strips were taken out of chromatographic chamber after complete run and dried at room temperature. They were sprayed with aniline-diphenylamine - orthophosphoric acid reagent by mixing them in the ratio of 5:5:1. Both aniline and diphenylamine were $4 \%$ in n-buanol separately. For each sample, two strips were run, one sprayed with the above reagent and the other was kept unsprayed. The sprayed strips were developed by placing them in the chromatographic oven at $90^{\circ} \mathrm{C}$ for 1-3 min. Developed spots (colored) on chromatograms were marked and Rf values calculated. On the basis of these $\mathrm{Rf}$ values spots were marked on the unsprayed chromatograms with a pencil. Individual spot covering an area was cut into small pieces and immersed in $3 \mathrm{ml}$ of DDW in test tube. Control set was prepared by eluting from an area (on the 
chromatogram) where no spot has developed. It was followed by adding $6 \mathrm{ml}$ of anthrone sulphuric acid reagent and prepared for the analysis of sugars (Mukherjee and Mukherjee, 2017). The absorbance was recorded at $630 \mathrm{~nm}$ using UV-Vis Spectrophotometer. The amount of individual sugar was determined with the help of a standard curve of glucose.

\section{$\alpha$-Amylase activity}

The method of Bernfeld (1951) was followed for the measurement of $\alpha$-amylase activity. One hundred mg of petal sample was used for each extraction. It was homogenized in $10 \mathrm{ml}$ DDW and centrifuged at $5000 \mathrm{rpm}(2124 \mathrm{RCF})$ and the supernatant was used for the enzymatic activity using 3, 5 dinitrosalicylic acid reagent (Mukherjee and Mukherjee, 2017). Specific activity was measured per mg protein. Amount of protein was estimated in terms of BSA by the method of Bradford (1976).

\section{Peroxidase activity}

The method of Maehly (1954) was followed to find out peroxidase activity. Petal sample weighing 100 mg was homogenized with $10 \mathrm{ml}$ of ice cold $0.1 \mathrm{M}$ $\mathrm{KH}_{2} \mathrm{PO}_{4}-\mathrm{Na}_{2} \mathrm{HPO}_{4}$ buffer of $\mathrm{pH} \quad 7.0$ and centrifuged in a Remi centrifuge at $5000 \mathrm{rpm}$ for $15 \mathrm{~min}$. Supernatant was collected and raised to 10 $\mathrm{ml}$ with the above mentioned ice cold phosphate buffer. Reaction set was prepared by mixing $2 \mathrm{ml}$ of enzyme extract, $2 \mathrm{ml}$ of phosphate buffer $(\mathrm{pH}$ $7.0), 2 \mathrm{ml}$ of guaiacol $(20 \mathrm{mM})$ and $2 \mathrm{ml}$ of $\mathrm{H}_{2} \mathrm{O}_{2}(10$ $\mathrm{mM}$ ) in a sequence. Blank set contains $2 \mathrm{ml}$ of enzyme extract, $2 \mathrm{ml}$ of phosphate buffer ( $\mathrm{pH}$ 7.0) and $4 \mathrm{ml}$ of DDW. The absorbance was recorded at $420 \mathrm{~nm}$ after $10 \mathrm{~min}$ in a Spectrophotometer. Specific peroxidase activity was expressed in terms of $\mathrm{mg}$ protein per $10 \mathrm{~min}$. Protein was estimated from the enzyme extract using Coomassie brilliant blue reagent (Bradford, 1976).

\section{Lipid peroxidation (MDA content)}

The level of lipid peroxidation of petal sample was estimated in terms of MDA content (Heath and Packer, 1968). Two hundred milligram petal sample was homogenized in $2 \mathrm{ml}$ of $50 \mathrm{mM}$ phosphate buffer ( $\mathrm{pH}$ 7.0). The homogenate was centrifuged at $10000 \mathrm{rpm}$ for $20 \mathrm{~min}$ in a Remi refrigerated centrifuge. To $0.5 \mathrm{ml}$ aliquot of the supernatant, $2 \mathrm{ml}$ of $0.5 \%$ thiobarbituric acid (TBA) in $20 \%$ trichloroacetic acid (TCA) was added. The mixture was heated at $90^{\circ} \mathrm{C}$ for $30 \mathrm{~min}$ in a water bath and then quickly cooled in an ice water bath. After centrifugation at $10000 \mathrm{rpm}$ for 10 min the absorbance of the supernatant was recorded at $532 \mathrm{~nm}$. The value for nonspecific absorption of each sample at $600 \mathrm{~nm}$ was also recorded and subtracted from the absorption recorded at $532 \mathrm{~nm}$. The concentration of MDA, an end product of lipid peroxidation was calculated in accordance to its extinction coefficient of 155 $\mathrm{mM}^{-1} \mathrm{~cm}^{-1}$ and expressed as nmol $\mathrm{g}^{-1} \mathrm{FW}$.

\section{Results and discussion}

Results have been incorporated in Tables 1-5. Table 1 shows flower diameter and volume of holding solutions absorbed by scapes during o-8 day. Flower diameter was $6.9 \mathrm{~cm}$ when experiment was started and it exhibited a decline at 4 and 8day due to shrinkage. Effectiveness of sucrose, kinetin $(\mathrm{KN})$ and salicylic acid (SA) was evident in these stages as they partly reduced the shrinkage phenomenon. Sucrose was the best when values of sucrose, $\mathrm{KN}$ and $\mathrm{SA}$ as vase solutions were compared. Reduction in diameter was further checked when sucrose was combined either with $\mathrm{KN}$ or SA. Additive effect of sucrose $+\mathrm{KN}$ was found to be best in arresting the decline in flower diameter. Among the treatments and control, maximum holding solution was absorbed in case of water as control followed by sucrose, SA and $\mathrm{KN}$. Minimum absorption of holding solution was noticed in case of sucrose $+\mathrm{KN}$ (Table 1). Onset of senescence and deterioration became faster in cut flowers in comparison to uncut ones. Cut flowers experience very rapid dehydration followed by wrinkles and shrinkage in petals. A gradual decline in turgidity has also been noticed. Sucrose and applied PGRs (KN and SA) helped to slow down the dehydration process. Such a behaviour of these compounds have been noticed in earlier investigation on Matricaria (Kaur and Mukherjee, 2012; Mukherjee and Mukherjee, 2017).

Amount of reducing, non-reducing and total sugars of Aster novae belgii has been shown in Table 2 . Amount of these sugars was minimum at o-day. They registered gradual increment both in control and treated scapes as depicted in their values between 0-4 and 4-8 day. Percent increase in the 
concentration of sugars was maximum between 0-4 day than 4-8 day. Sucrose and two PGRs (KN and $\mathrm{SA}$ ) were unique in minimizing this accumulation in both the kinds of sugars but it was more prominent in reducing sugars. The most effective application in controlling accumulation of reducing and nonreducing sugars was $\mathrm{KN}$ + sucrose followed by SA + sucrose, sucrose, KN, SA and control. Accumulation of both kinds of sugars at senescent phase has been reported in Calendula officinalis (Khokhar and Mukherjee, 2010 a, b; Kaur and Mukherjee, 2013), Arctotis grandis (Khokhar and Mukherjee, 2010b), Chrysanthemum dendranthema grandiflorum var. Chandrima (Kaur and Mukherjee, 2016) and Matricaria parthenium (Mukherjee and Mukherjee, 2017).

Table 1. Aster novae belgii L. showing flower diameter (in $\mathrm{cm}$ ) and volume of holding solutions (in ml) absorbed by scapes when they were placed in conical flasks having various holding solutions (Double distilled water, DDW = control; sucrose 0.1 M; kinetin $=\mathrm{KN}, 37.5 \mu \mathrm{M}$ concentration; $\mathrm{KN}+$ sucrose $0.1 \mathrm{M}$; salicylic acid $=\mathrm{SA}, 37.5 \mu \mathrm{M}$ concentration; SA + sucrose $0.1 \mathrm{M}$ ). [o-Day values of flower diameter and holding solutions were $6.9 \mathrm{~cm}$ and $30 \mathrm{ml}$ respectively].

\begin{tabular}{|c|c|c|c|c|c|c|c|}
\hline \multirow[t]{2}{*}{ Treatments } & \multicolumn{2}{|c|}{ Flower diameter* } & \multicolumn{3}{|c|}{ \% Difference in flower diameter } & \multirow{2}{*}{$\begin{array}{l}\begin{array}{l}\text { Vol. of } \\
\text { solution } \\
\text { absorbed* }\end{array} \\
\text { o-8 Day } \\
\end{array}$} & \multirow{2}{*}{$\begin{array}{l}\text { \% of holding } \\
\text { solution } \\
\text { absorbed } \\
\text { o-8 Day } \\
\end{array}$} \\
\hline & 4-Day & 8-Day & o-4 Day & 4-8 Day & o-8 Day & & \\
\hline Control (DDW) & $5 \cdot 5$ & 4.8 & 20.29 & 12.73 & 30.43 & 25.5 & 85 \\
\hline Sucrose & 6.5 & 5.8 & 5.80 & 10.77 & 15.94 & 20.5 & 68.33 \\
\hline KN & 6.3 & 5.4 & 8.70 & 14.29 & 21.74 & 13.5 & 45 \\
\hline KN + Sucrose & 6.7 & 6.0 & 2.90 & 10.45 & 13.04 & 10.5 & 35 \\
\hline SA & 6.1 & 5.1 & 11.59 & 16.39 & 26.09 & 16.5 & 55 \\
\hline $\mathrm{SA}+$ Sucrose & 6.4 & 5.0 & 7.25 & 21.88 & 27.88 & 14.5 & 48.33 \\
\hline
\end{tabular}

*Each value indicates mean of 10 replicates

Table 2. Aster novae belgii L. showing amount of reducing, non-reducing and total sugars (mg/10omg dry weight \pm S.E.) in petals of cut flowers when scapes were placed in conical flasks having various holding solutions (Double distilled water, DDW= control; sucrose $0.1 \mathrm{M}$; kinetin $=\mathrm{KN}, 37.5 \mu \mathrm{M}$ concentration; $\mathrm{KN}+$ sucrose $0.1 \mathrm{M}$; salicylic acid = SA, $37.5 \mu \mathrm{M}$ concentration, SA + sucrose $0.1 \mathrm{M}$ ). [0- Day values of reducing, non-reducing and total sugars were $0.987 \pm 0.86,0.50 \pm 0.156$ and $1.48 \pm 0.208 \mathrm{mg} / 100 \mathrm{mg}$ respectively].

\begin{tabular}{lllll}
\hline Days & Treatments & Reducing sugars & Non-reducing sugars & Total sugars \\
\hline 4-Day & Control (DDW) & $5.88 \pm 0.073(+495 \cdot 74)$ & $2.96 \pm 0.545(+492)$ & $8.84 \pm 0.488(+497.30)$ \\
& Sucrose & $2.83 \pm 0.220(+186.72)$ & $2.06 \pm 0.368(+312)$ & $4.90 \pm 0.169(+231.08)$ \\
& KN & $3.39 \pm 0.066(+243.46)$ & $2.41 \pm 0.160(+382)$ & $5.86 \pm 0.193(+295.94)$ \\
& KN + Sucrose & $1.99 \pm 0.437(+101.62)$ & $0.99 \pm 0.157(+98.0)$ & $2.99 \pm 0.340(+102.02)$ \\
& SA & $3.50 \pm 0.361(+254.61)$ & $2.81 \pm 0.524(+462)$ & $6.31 \pm 0.245(+326.35)$ \\
& SA + Sucrose & $2.18 \pm 0.098(+120.87)$ & $1.32 \pm 0.062(+164)$ & $3.51 \pm 0.153(+137.16)$ \\
8-Day & Control (DDW) & $8.17 \pm 0.059(+727.76)$ & $5.09 \pm 0.208(+918)$ & $13.26 \pm 0.208(+795.94)$ \\
& Sucrose & $3.52 \pm 0.008(+256.63)$ & $2.83 \pm 0.120(+466)$ & $6.36 \pm 0.125(+329.72)$ \\
& KN & $4.47 \pm 0.056(+352.88)$ & $3.48 \pm 0.291(+596)$ & $7.95 \pm 0.261(+437.16)$ \\
& KN + Sucrose & $2.66 \pm 0.040(+169.50)$ & $1.31 \pm 0.351(+162)$ & $3.96 \pm 0.393(+167.56)$ \\
& SA & $4.89 \pm 0.141(+395.44)$ & $3.88 \pm 0.102(+676)$ & $8.78 \pm 0.160(+493.24)$ \\
& SA +Sucrose & $3.04 \pm 0.059(+208.00)$ & $1.82 \pm 0.231(+264)$ & $4.87 \pm 0.260(+229.05)$ \\
\hline
\end{tabular}

Data in parenthesis indicate percent change from 0 -Day values.

Paper chromatographic separation of sugars detected glucose and fructose only (Table 3 ). The levels of glucose and fructose were considerably lower initially than later stages in petals. Remarkable increase in both sugars was observed after 4 and 8 days in control vase solution. The rise in sugars was much greater between 0-4 day than 4-8 day in control and treated scapes. It was interesting to note that petal sugars markedly declined in presence of sucrose than DDW as 
control. $\mathrm{KN}$ and SA as vase solutions also helped in reducing levels of glucose and fructose but their effectiveness was lower than that of sucrose. The amount of these individual sugars declined further in presence of $\mathrm{KN}+$ sucrose and $\mathrm{SA}+$ sucrose. Greater accumulation of sugars in untreated cut flower petals may indicate higher requirement of energy and carbon. But, presence of sucrose, $\mathrm{KN}$ and SA brought down this requirement.

Petals of A. novae belgii was characterized by a higher amount of starch and lower $\alpha$-amylase activity at initial (o-day) stage. However, petals of cut flowers between 0-4 and 4-8 day showed a steady decline in the former and increment in latter (Table 4). Sucrose and two PGRs in vase solutions were unique in partially retaining the amount of starch by regulating $\alpha$-amylase activity. Combined application of $\mathrm{KN}+$ sucrose was really effective and the best among all treatments for controlling starch depletion. Lesser degradation of starch in presence of sucrose, $\mathrm{KN}$ and SA may explain why the amount of sugars was lower in these cases than in the controls.

Table 3. Aster novae belgii L. showing the amount of individual sugars (mg/10omg dry weight) in petals of cut flowers when scapes were placed in conical flasks having various holding solutions (Double distilled water, DDW, control; sucrose $0.1 \mathrm{M}$; kinetin=KN, $37.5 \mu \mathrm{M}$ concentration; $\mathrm{KN}+$ sucrose $0.1 \mathrm{M}$; salicylic acid $=\mathrm{SA}, 37.5 \mu \mathrm{M}$ concentration; SA+ sucrose 0.1M). [o-Day values of glucose and fructose were 0.125 and $0.062 \mathrm{mg} / 100 \mathrm{mg}$ respectively].

\begin{tabular}{llll}
\hline Days & Treatments & Glucose & Fructose \\
\hline 4-Day & Control (DDW) & $1.803(+1342.4)$ & $0.937(+1411.29)$ \\
& Sucrose & $0.971(+676.8)$ & $0.298(+380.64)$ \\
& KN & $1.121(+796.8)$ & $0.350(+464.52)$ \\
& KN + Sucrose & $0.671(+436.8)$ & $0.241(+288.71)$ \\
& SA & $1.510(+1108)$ & $0.442(+612.90)$ \\
& SA + Sucrose & $0.742(+493.6)$ & $0.269(+333.87)$ \\
8-Day & & \\
& Control (DDW) & $2.170(+1636)$ & $1.675(+2601.61)$ \\
& Sucrose & $1.021(+716.8)$ & $0.889(+1333.87)$ \\
& KN & $1.288(+930.4)$ & $1.137(+1733.87)$ \\
& KN + Sucrose & $0.782(+525.6)$ & $0.693(+1017.74)$ \\
& SA & $1.471(+1076.8)$ & $1.328(+2041.93)$ \\
& SA + Sucrose & $0.862(+589.6)$ & $0.757(+1120.97)$ \\
\hline
\end{tabular}

Data in parenthesis indicate percent change from o-Day values.

Table 4. Aster novae belgii L. showing the amount of starch (mg/10omg dry weight \pm S.E.) and specific activity of $\alpha$ amylase (unit per mg protein \pm S.E.) in petals of cut flowers when scapes were placed in conical flasks having various holding solutions (Double distilled water, DDW, control; sucrose $0.1 \mathrm{M}$; kinetin $=\mathrm{KN}, 37.5 \mu \mathrm{M}$ concentration; $\mathrm{KN}+$ sucrose 0.1M; salicylic acid = SA, 37.5 $\mu \mathrm{M}$ concentration; SA + sucrose 0.1M). [0-Day values of starch and $\alpha$-amylase activity were $36.59 \pm 1.200$ and $0.691 \pm 0.045$ respectively].

\begin{tabular}{llll}
\hline Days & Treatments & Starch & $\alpha$-Amylase activity \\
\hline 4-Day & Control (DDW) & $18.99 \pm 0.250(-48.10)$ & $7.14 \pm 0.337(+933.28)$ \\
& Sucrose & $22.52 \pm 0.931(-38.45)$ & $2.96 \pm 0.179(+328.36)$ \\
& KN & $23.09 \pm 1.514(-36.90)$ & $3.13 \pm 0.400(+352.97)$ \\
& KN + Sucrose & $28.32 \pm 2.892(-22.60)$ & $1.82 \pm 0.149)(+163.39)$ \\
& SA & $22.23 \pm 1.519(-39.25)$ & $4.50 \pm 0.194(+551.23)$ \\
8-Day & SA + Sucrose & $24.78 \pm 2.268(-32.28)$ & $2.41 \pm 0.121(+248.77)$ \\
& Control (DDW) & $7.19 \pm 0.176(-80.35)$ & $17.99 \pm 0.650(+2503.47)$ \\
& Sucrose & $11.10 \pm 0.261(-69.66)$ & $5 \cdot 32 \pm 0.389(+669.90)$ \\
& KN & $10.63 \pm 0.579(-70.95)$ & $6.19 \pm 0.209(+795.80)$ \\
& KN + Sucrose & $14.23 \pm 1.020(-61.11)$ & $4.39 \pm 0.195(+535.31)$ \\
& SA & $9.37 \pm 1.032(-74.39)$ & $8.15 \pm 0.681(+1079.45)$ \\
& SA + Sucrose & $12.80 \pm 1.560(-65.02)$ & $5.03 \pm 0.325(+627.93)$ \\
\hline
\end{tabular}

Data in parenthesis indicate percent change from o-Day values. 
Table 5 shows peroxidase activity and MDA content in petals of $A$. novae belgii scapes maintained in DDW and other vase solutions containing sucrose, $\mathrm{KN}, \mathrm{SA}, \mathrm{KN}+$ sucrose and SA + sucrose. At the time of experiment setting, values of both parameters were much lower than subsequent stages. Control samples recorded 556.39 percent and 990.22 percent increase between 0-4 and 4-8 day stages in peroxidase activity. The rate of increment was much slower after treatments. Among sucrose, $\mathrm{KN}$ and SA, least peroxidase activity was obtained with sucrose followed by $\mathrm{KN}$ and $\mathrm{SA}$. However, combined application of $\mathrm{KN}+$ sucrose could further lower the enzymatic activity. This was also true for SA+sucrose treatment. Some of our earlier studies with Calendula officinalis cut and uncut flowers at the advanced stages of development and senescence also showed considerable increase in peroxidase activity (Kaur et al., 2015; Kaur and Mukherjee, 2015; Singh et al., 2018). Present study has revealed that sucrose and PGRs like KN and SA when present alone and also in combination ( $\mathrm{KN}+$ sucrose and $\mathrm{SA}+$ sucrose) were very effective in slowing down the enzymatic activity.

Table 5. Aster novae belgii L. showing peroxidase activity (unit per mg protein per $10 \mathrm{~min} . \pm$ S.E.) and MDA content $\left(\mathrm{nM} \mathrm{g}^{-1}\right.$ fresh weight \pm S.E.) in petals of cut flowers when scapes were placed in conical flasks having various holding solutions (Double distilled water, DDW, control; sucrose $0.1 \mathrm{M}$; kinetin $=\mathrm{KN}, 37.5 \mu \mathrm{M}$ concentration; $\mathrm{KN}+$ sucrose o.1M; salicylic acid = SA, 37.5 $\mu \mathrm{M}$ concentration; SA + sucrose 0.1M). [0-Day values of peroxidase activity and MDA content were $1.33 \pm 0.145$ and $0.00240 \pm 0.00015$ respectively].

\begin{tabular}{llll}
\hline Days & Treatments & Peroxidase Activity & MDA Content \\
\hline 4-Day & Control (DDW) & $8.73 \pm 0.272(+556.39)$ & $0.00826 \pm 0.00018(+244.16)$ \\
& Sucrose & $2.47 \pm 0.293(+85.71)$ & $0.00543 \pm 0.000086(+126.25)$ \\
& KN & $2.93 \pm 0.499(+120.30)$ & $0.00576 \pm 0.000069(+140)$ \\
& KN + Sucrose & $1.62 \pm 0.272(+21.80)$ & $0.00343 \pm 0.000086(+42.92)$ \\
& SA & $3.22 \pm 0.672(+142.10)$ & $0.00640 \pm 0.000086(+166.66)$ \\
& SA + Sucrose & $1.99 \pm 0.133(+49.62)$ & $0.00460 \pm 0.000057(+91.66)$ \\
$8-$ Day & & \\
& Control & $14.50 \pm 0.290(+990.22)$ & $0.01450 \pm 0.00018(+504.16)$ \\
& Sucrose & $4.74 \pm 0.549(+256.39)$ & $0.00730 \pm 0.000086(+204.16)$ \\
& KN & $5.41 \pm 0.577(+306.76)$ & $0.00886 \pm 0.000057(+269.16)$ \\
& KN + Sucrose & $3.27 \pm 0.577(+145.86)$ & $0.00660 \pm 0.00015(+175)$ \\
& SA & $6.06 \pm 0.214(+355.64)$ & $0.00980 \pm 0.000057(+308.33)$ \\
& SA + Sucrose & $4.08 \pm 0.111(+206.76)$ & $0.00830 \pm 0.000098(+245.83)$ \\
\hline
\end{tabular}

Data in parenthesis indicate percent change from o-Day values.

One of the common observations during petal senescence is the rapid increment in lipid peroxidation (Jones and Mc.Conchie, 1995; Fukuchi-Mizutani et al., 2000). This study also showed a gradual increase in lipid peroxidation which is measured as the amount of MDA formed. Sucrose as vase solution was very useful in lowering this process. $\mathrm{KN}$ and $\mathrm{SA}$ were also effective in arresting this process partly (Table 5). This process of membrane breakdown increased with the passage of time; 8 th day value was much higher than that of 4 th day. Lipid peroxidation causes disintegration of membranous proteins and produces aldehydes and ketones (Valentine et al., 1998; Wilhelmova et al., 2006). MDA is a common end product and a sensitive diagnostic index of oxidative injury (Janero, 1990). Combined effect of
$\mathrm{KN}+$ sucrose was the best in controlling the increase in MDA level.

\section{Conclusion}

Cut flower petals of $A$. novae belgii experienced very quick dehydration followed by appearance of wrinkles and loss of turgidity. Flower diameter decreased and maximum holding solution was absorbed in DDW maintained scapes. Rapid breakdown of starch, increment in the activity of $\alpha$ amylase and peroxidase, accumulation of sugars and rise in MDA content were noticed in petals of control scapes. Sucrose, KN and SA were effective in minimizing the reduction in flower diameter, arresting starch depletion, lowering $\alpha$-amylase and peroxidase activity; and useful in decreasing lipid 
peroxidation and sugar concentration. A combination of $\mathrm{KN}+$ sucrose was the best followed by SA + sucrose in delaying petal senescence.

\section{Conflict of interest statement}

Authors declare that they have no conflict of interest.

\section{Acknowledgement}

The financial assistance to D. Mukherjee from Indian Science Congress Association, Kolkata for providing Asutosh Mookerjee Fellowship is gratefully acknowledged. Authors are also grateful to Chairman, Department of Botany, Kurukshetra University, Kurukshetra for laboratory facilities.

\section{References}

Beevers, L., 1976. Senescence. In: Plant Biochemistry (Eds.: Bonner, J., Varner, J.E.), Academic Press, New York, San Francisko and London, pp. 771-794.

Bernfeld, P., 1951. Amylase $\alpha$ and $\beta$. In: Methods in Enzymology (Eds.: Colowick, S.P., Kaplan, N.O.). Academic Press, New York, pp. 149-158.

Bradford, M.M., 1976. A rapid and sensitive method for the quantitation of microgram quantities of proteins utilizing the principle of protein-dye binding. Anal. Biochem. 72, 248254.

Fukuchi-Mizutani, M., Ishiguro, K., Nakayama, T., Utsunomiya, Y., Tanaka, Y., Kusumi, T., Ueda, T., 2000. Molecular and functional characterization of a rose lipoxygenase cDNA related to flower senescence. Plant Sci. 160, 129-137.

Hart, F.L., Fisher, H.J., 1971. Modern Food Analysis. Springer-Verlag, Berlin-Heidelburg New York.

Heath, R.L., Packer, L., 1968. Photoperoxidation in isolated chloroplast I. Kinetics and stoichiometry of fatty acid peroxidation. Arch. Biochem. Biophys. 125, 189-198.

Janero, D.R., 1990. Malondialdehyde and thiobarbituric acid reactivity as diagnostics indices of lipd peroxidation and peroxidative tissue injury. Free Radic. Biol. Med. 9, 515-540.

Jones, R., Mc Conchie, R., 1995. Characteristics of petal senescence in a non-climacteric cut flower. Acta Hort. 405, 216-223.
Kaur, P., Mukherjee, D., 2012. Delaying postharvest senescence of Matricaria parthenium L. flowers using ethanol, methanol and sucrose. J. Trop. Plant Physiol. 4, 1-16.

Kaur, P., Mukherjee, D., 2013. Senescence regulation by alcohols in cut flowers of Calendula officinalis L. Acta Physiol. Plant. 35, 1853-1861.

Kaur, P., Singh, Narender, Mukherjee, D., 2015. Regulation of membrane leakage and activities of some antioxidant enzymes in petals of cut flowers of Calendula officinalis and Salvia splendens with metabolites and plant growth regulators. J. Appl. Hortic. 17(1), 31-39.

Kaur, P., Mukherjee, D., 2015. L-Serine and spermine delay petal senescence in cut flowers of Calendula officinalis L. Life Sci. Leaflet. 69, 112-124.

Kaur, P., Mukherjee, D., 2016. Post-harvest physiology and vase life of cut Chrysanthemum flowers with sucrose, putrescine and spermidine as holding solutions. J. Indian Bot. Soc. 95(1\&2), 105-115.

Khokhar, M., Mukherjee, D., 2010a. Role of plant growth regulator in petal senescence of Calendula officinalis $\mathrm{L}$. and Coreopsis lanceolata L. J. Indian Bot. Soc. 89, 37-43.

Khokhar, M., Mukherjee, D., 2010b. Senescence regulation in cut flowers of Calendula officinalis L. and Arctotis grandis Thunb. with kinetin, salicylic acid and a morphactin. J. Plant Biol. 37, 215-222.

Kuiper, D., Ribot, S., van Reenen, H.S., Marrissen, N., 1995. The effect of sucrose on the flower bud ripening of 'Madelon' cut roses. Scien. Hort. 6o, 325-336.

Maehly, A. C., 1954. Determination of peroxidase activity. Inter Science Publisher Inc., New York 1, 385-386.

Monteiro, J.A., Nell, T.A., Barrett, J.E., 2002. Effects of exogenous sucrose on carbohydrates levels, flower respiration and longevity of potted miniature rose (Rosa hybrida) flowers during post production. Postharvest Biol. Technol. 26, 221-229.

Mukherjee, S., Mukherjee, D., 2017. Additive effects of sucrose with kinetin and salicylic acid in delaying petal senescence of cut flowers of Matricaria parthenium L. Int. J. Curr. Res. Biosci. Plant Biol. 4(11), 86-95.

Mukherjee, S., Singh, S., Jakhar, S., Mukherjee, D., 2019. Postharvest regulation of petal 
senescence in Gaillardia pulchella Foug. scapes by sucrose, 8- hydroxyquinoline and methylchlorflurenol individually and in combination as vase solution. J. Indian Bot. Soc. 98(1), 37-44.

O'Donoghue, E.M., Somerfield, S.D., Heyes, J.A., 2002. Vase solutions containing sucrose result in changes to cell walls of Sandersonia (Sandersonia aurantiaca) flowers. Postharvest Biol. Technol. 26, 285-294.

Rubinstein, B., 2000. Regulation of cell death in flower petals. Plant Mol. Biol. 44, 303-318.

Singh, S., Mukherjee, S., Jakhar, S., Mukherjee, D., 2018. Interaction of sucrose, a morphactin and 8-hydroxyquinoline in the regulation of petal senescence of Calendula officinalis cut flowers. Int. J. Curr. Res. Biosci. Plant Biol. 5(12), 28-38.

Stead, A.D., van Doorn, W.G., 1994. Strategies of flower senescence-A review. In: Molecular and Cellular Aspects of Plant Reproduction (Eds.: Scott, R.J., Stead, A.D.), Cambridge University Press, Cambridge, UK, pp. 215-238.

Valentine, J.S., Wertz, D.L., Lyons, T.L., Liou, L.L., Gotto, J.J., Gralla, E.B., 1998. The dark side of dioxygen biochemistry. Curr. Opin. Chem. Biol. 2, 253-262.

van Doorn, W.G., 2004. Is petal senescence due to sugar starvation? Plant Physiol. 134, 35-42.

Wilhelmova, N., Dominques, P.M.D.N., Srbova, M., Fuksova, H., Wilhelm, J., 2006. Changes in nonpolar aldehydes in bean cotyledons during ageing. Biol. Plant. 50, 559-564.

Woltering, E.J., van Doorn, W.G., 1988. Role of ethylene in senescence of petals, morphological and taxonomical relationships. J. Exp. Bot. 39, 139-145.

\section{How to cite this article:}

Mukherjee, S., Mukherjee, D., 2020. Individual effects of sucrose, kinetin and salicylic acid and combined effects of kinetin + sucrose and salicylic acid + sucrose in petal senescence regulation of Aster novae belgii L. Int. J. Curr. Res. Biosci. Plant Biol. 7(2), 14-21. doi: https://doi.org/10.20546/ijcrbp.2020.702.003 